\title{
"FUTEBOL TAMBÉM É COISA DE MENINA": UM ESTUDO SOBRE O GÊNERO FEMININO NA ESCOLA
}

\author{
"SOCCER IS ALSO FOR GIRLS": A STUDY ABOUT THE FEMALE GENDER AT SCHOOL
}

\author{
Anilse Maria Pícollo Borttolin
}

RESUMO: Neste artigo, apresenta-se um estudo sobre o gênero feminino nas três turmas de sétimas séries do período vespertino da E.E.B. Natálio Vassoler, Forquilhinha (SC), tendo como objetivo identificar e analisar como as meninas são tratadas e como elas reagem perante as oportunidades ou impedimentos nas práticas esportivas, quando o assunto é o futebol na escola. A abordagem teórica vincula-se às reflexões de LOURO (1997), COSTA (2001), SARTORI (2004) e CONNELL (2009), levando em consideração documentos como os PCNs: terceiro e quarto ciclos do ensino fundamental (1998), PCNs: Educação Física (1998), entre outros. Os dados do estudo são compostos por produções textuais escritas, como opiniões relatadas em um breve depoimento pelos meninos e meninas das referidas séries, a partir da leitura, compreensão e discussão do texto "Futebol também é coisa de menina", do livro didático de Língua Portuguesa do 4ํ ano do ensino fundamental de Prado e Hülle, uma reportagem publicada pela revista Recreio, da Editora Abril, do mês de maio de 2000. 0 trabalho permitiu compreender que as relações sexistas nessas turmas reforçam a existência de desigualdade entre os meninos e meninas no espaço esportivo escolar, do qual as meninas ainda se sentem excluídas. Percebe-se que há diferenças nas funções sociais que vivem e nos quais continuam visualizando os valores construídos socialmente ao longo do tempo.

Palavras-chave: gênero feminino; desigualdade; inclusão; futebol na escola.

ABSTRACT: This article discussed a study about the female gender in three classes at E.E.B. Natálio Vassoler, Forquilhinha (SC), to identify and analyze how girls are treated and how they react to the opportunities or obstacles to playing sports, when the subject is soccer at school. The theoretical background was based on LOURO (1997), COSTA (2001), SARTORI (2004), and CONNELL (2009), as well as documents like the PCNs for the $3^{\text {rd }}$ and $4^{\text {th }}$ grades (1998) and PCN - Physical Education (1998) among others. The data for this study was compounded by texts produced by boys and girls, following the reading and discussion of "Futebol também é coisa de menina," (Soccer is also for girls) from the Portuguese Language Book for $4^{\text {th }}$ grade by Prado and Hülle, a report published by Recreio, in May 2000. The research project provides further understanding of the sexist relationships in these classes and confirms the inequality between boys and girls at school, which makes girls feel excluded from sports. It reveals differences in social function that they live with and continue to view as social values formed over time.

Keywords: female gender; inequality; inclusion; soccer at school.

\footnotetext{
${ }^{1}$ Mestranda do Programa de Pós-Graduação Stricto Sensu em Educação - UNESC. Professora de Língua Portuguesa e Inglesa na E.E.B. Natálio Vassoler - Vila Franca - Forquilhinha/SC.

E-mail: nicepicollo@hotmail.com
} 


\section{INTRODUÇÃO}

Atualmente, o papel da mulher na sociedade torna-se cada vez mais intensificado e são diversos os exemplos de mulheres que a todo 0 instante vêm conseguindo e garantindo os espaços de grande sucesso nos mais variados setores da sociedade que antes eram apenas dominados pelos homens. O futebol, considerado um esporte nacional e até internacional, apresenta-se intensivamente como uma dessas áreas da sociedade, que atualmente ainda continua com maior participação dos homens, seja como jogadores, torcedores ou trabalhadores relacionados diretamente ao futebol, mas pode-se dizer que ainda há esperanças de mudança positivas dessa situação, pois começam a surgir algumas ações que podem contribuir para amenizar tal manifestação que está em alta a cada dia que passa.

Apresenta-se como questão investigativa, qual a função que o gênero feminino das três turmas de sétimas séries do período vespertino da E.E.B. Natálio Vassoler, Forquilhinha (SC), desempenha na área esportiva, tendo como objetivo identificar e analisar como as meninas se comportam ao se sentirem incluídas/excluídas das oportunidades das aulas de Educação Física, bem como saber a maneira como elas reagem perante a leitura, interpretação e compreensão do texto "Futebol também é coisa de menina", retirada da página 187 , do livro didático de Língua Portuguesa, do $4^{\circ}$ ano do ensino fundamental, de Angélica Prado e Cristina Hülle, uma reportagem publicada pela revista Recreio, da Editora Abril, do mês de maio de 2000. Pretende-se refletir sobre as referidas relações e a função que essas meninas desempenham nas atividades esportivas das três sétimas séries do período vespertino, no ano de 2010, cujo assunto é o dito futebol.

Direcionando melhor o trabalho, procura-se contextualizar as principais discussões escritas pelas meninas e meninos sobre a função que o gênero feminino pode desempenhar em atividades físicas e esportivas como o futebol na escola, analisar as opiniões sobre a inclusão/exclusão das meninas no contexto do futebol e ver como as meninas reagem perante tais constrangimentos de exclusão das quais elas revelam em suas discussões quando se fala em futebol.

Ao questionar sobre gênero, cita-se Louro (2001), que afirma que existem inúmeras teorias e explicações para averiguar as distinções entre homens e mulheres, porém esses estudos procuram desvendar entendimentos muito mais do que as simples distinções. Segundo a autora, os estudiosos vêm procurando demonstrar que não são as características sexuais, mas sim tudo o que se diz ou se pensa sobre elas, tudo o que representa e tudo o que é valorizado ou desvalorizado em relação aos sexos que constitui o masculino e o feminino numa dada sociedade e num momento histórico. Ou seja, gênero é como se apresentam na sociedade as diferenças percebidas entre os sexos, sejam elas biológicas e sociais ou culturalmente construídas.

Atualmente, em todo contexto social, tenta-se equilibrar a relação entre os gêneros no sentido de que homens e mulheres construam os mesmos direitos e se sintam incluídos nas mais diversificadas situações e oportunidades. Esse José dos Campos-SP, v. 17, n. 30, dez.2011. ISSN 2237-1753 
pensamento deve-se associar também à escola a partir do trabalho dos professores e toda comunidade escolar para que haja a inclusão dos gêneros: tanto masculino quanto feminino nas suas atividades mesmo que sejam as esportivas.

\section{A REPRESENTAÇÃO DO GÊNERO FEMININO E MASCULINO NO MEIO SOCIAL}

A função social das mulheres normalmente ocupou uma posição de inferioridade em relação ao desempenho dos homens, pois a relação que existia entre os gêneros era de real dominação na história. Por muito tempo, a mulher realmente foi considerada como um ser fraco, no sentido físico e intelectualmente, quando vista em referência ao homem, ficando esse geralmente ao centro das melhores oportunidades que a sociedade teria a fornecer.

Diante de tal realidade social, as pessoas pensam de forma natural sobre o fato de que alguns homens dominem os outros, firmando-se uma verdade que vai passando de geração em geração. Esse procedimento de dominação, portanto, pode ajudar a explicar, em alguns casos, a submissão marcada historicamente que abrange as mulheres em face aos homens. Considera-se, então, o homem como o responsável principal pela família, aquele que sustenta a casa, trabalhando fora, aquele que participa dos esportes com conhecimento, habilidade e liberdade, o que tem dinheiro, ficando a mulher vista como um ser quase inútil, restando-Ihe, apenas, o trabalho da própria casa, desvalorizada, nem vista pelos seus talentos, e, ainda, na função de cuidar dos filhos e sem a possibilidade de envolver-se nas atividades esportivas.

A categoria gênero masculino e feminino, segundo Louro (1997), surgiu na constituição dos movimentos feministas do século $X X$ e foi realçada especificamente a partir da década de 1960, quando o movimento feminista tornou-se mais visível no meio social. Mas seu reconhecimento iniciou-se na década de 1930 com o movimento do "sufragismo", que significa a "primeira onda" do feminismo, o qual representou a luta pelo direito das mulheres ao voto, e com as reivindicações ligadas à organização familiar, oportunidade de emprego e direito à profissão. Dessa forma, as mulheres, no início do século passado, tiveram um papel desafiante na sociedade, demonstrando uma total mudança de atitude ao buscarem e lutarem pelo verdadeiro valor e reconhecimento dos seus direitos enquanto mulheres e cidadãs.

No entanto, apesar das lutas em busca dos direitos da mulher, ela ainda enfrenta obstáculos com o preconceito masculino, de modo que as ideias existentes por muito tempo estão ainda presentes nas falas e atitudes dos homens e das instituições por eles vividas. Apesar de o futebol feminino ter conquistado cada vez mais o espaço na própria sociedade brasileira, ainda há muita resistência por parte de alguns homens. Talvez por uma necessidade de afirmação, os homens ainda querem mostrar-se como seres principais e superiores sobre todas as coisas. Dessa forma, no ambiente social em que vivemos, tende-se a manter ainda, em alguns casos, a desvalorização da mulher, 
partindo-se do princípio de que ela em si pouco ou nada significa e de que deve esquecer-se de si e dos seus interesses e dedicar-se apenas às atividades corriqueiras como cuidar da casa, dos filhos ou do marido, sem exercer qualquer atividade esportiva que não seja considerada delicadamente feminina.

Entretanto, hoje, a perspectiva que se tem aponta para que esse tipo de mulher fraca e que só serve para cuidar dos afazeres da casa, se transforme, permitindo um lugar a uma mulher mais dinâmica, habilidosa e inserida no mundo do trabalho fora de casa, mulher trabalhadora que conquista cada vez mais o espaço no mundo profissional, da política, das lutas sindicais, dos esportes, dentre outros, espaços antes considerados apenas masculinos. Contudo, é lamentável que esses locais ainda permaneçam recheados de preconceitos, discriminações e exclusões definidas pelas pessoas que não conseguem atualizar sua visão nesse contexto.

As mudanças percebidas nessa área indicam que alguns fatores importantes têm contribuído, como, por exemplo, a necessidade financeira, que força a entrada cada vez maior da mulher no mercado de trabalho, o aumento crescente por mulheres que chefiam e até sustentam a família, a organização das mulheres lutando por mais igualdade nos direitos legais, lideranças sindicais e entre outros fatores que influenciam diariamente a sua vivência e contribuem para defender a sua adaptação e autonomia no meio social.

Para tanto, nota-se que seja necessário pensar qual a função da mulher nesta sociedade excludente que a represa em todos os ambientes sociais, inclusive no espaço escolar e esportivo, fortemente representado no jogo de futebol. Segundo Louro, ainda existem aqueles que justificam as desigualdades atribuindo-as às características biológicas.

É neste argumento que homens e mulheres são biologicamente distintos e que a relação entre ambos decorre desta distinção, que é complementar e na qual cada um deve desempenhar um papel determinado secularmente, acaba por ter o caráter de argumento final, irrecorrível (LOURO, 1997, p. 20-21).

Sendo assim, seja em qualquer lugar, a distinção sexual serve para compreender e justificar a desigualdade social. No entanto, a autora acha necessário demonstrar que não são as características sexuais que devem ser determinantes, porém a forma como essas características são representadas e valorizadas. $O$ que realmente constitui o masculino e 0 feminino é aquilo que se diz ou se pensa sobre essas características em determinada sociedade e época. E ela confirma: "Para que se compreenda o lugar $e$ as relações de homens e mulheres numa sociedade importa observar não exatamente seus sexos, mas sim tudo o que socialmente se construiu sobre os sexos" (LOURO, 1997, p. 21).

Apesar de serem conceitos relacionados, sexo e gênero possuem significados distintos, pois as diferenças de sexo estão relacionadas a aspectos biológicos, enquanto as diferenças de gênero são estabelecidas por intermédio do meio social em que vivemos.

Para se compreender o lugar e as 
relações de homens e mulheres numa sociedade, importa observar não exatamente seus sexos, mas tudo o que socialmente se constitui sobre os sexos. Nesta sentença, Louro (1997, p. 22) faz refletir que "o gênero se constitui com ou sobre corpos sexuados, ou seja, não é negada a biologia, mas enfatizada, deliberadamente, a construção social e histórica produzida sobre as características biológicas". De acordo com Connell (1995, p. 189, apud LOURO, 1997, p. 22), "No gênero, a prática social se dirige aos corpos". A autora, então, acrescenta que o conceito se refere à maneira como as características sexuais são compreendidas e representadas ou como são trazidas para a prática social e como se tornam parte do processo histórico.

Diante da discussão sobre gênero e sexualidade, pode-se considerar que a igualdade entre homens e mulheres inclui e depende do reconhecimento da existência da diferença, e como revela Louro (1997, p. 22), "As justificativas não devem ser buscadas nas diferenças biológicas, mas nos arranjos sociais, na história, nas condições de acesso aos recursos da sociedade e nas suas representações".

\subsection{A questão das meninas e meninos na escola}

As relações construídas pelas desigualdades sociais são muitas entre os vários lugares que as pessoas ocupam, vivem e, além disso, nas falas que produzem. Ressalta-se que a escola é um desses espaços. Diferenças, distinções e constrangimentos... A escola produz esses efeitos desde seu início, como instituição direcionada à educação. Foi ali que se iniciou a ideia de separar os meninos das meninas tornando-os distintos em seu acesso ao aprendizado, nas coisas que fazem e entre outros exemplos que determinaram tal distanciamento entre eles.

Segundo Sartori e Britto (2004, p. 53), "Os estudos da pedagogia demonstram que a escola é um lugar onde se produzem, onde se reproduzem e se cristalizam distinções...", algo que Michel Foucault analisa detalhadamente em Vigiar e Punir (2004), a escola como produtora de hierarquias e corpos dóceis. A diversidade e a desigualdade nesse ambiente são percebidas, algumas vezes, de maneira negativa ou positiva em relação às diferenças socialmente apresentadas. Dentre algumas áreas de ensino no ambiente escolar, a Educação Física é um dos meios em que fica mais evidente a separação entre meninos e meninas a partir da habilidade e da capacidade físicas dos alunos. Atualmente, nota-se que ainda permanece a ideia de que as meninas são menos capazes que os meninos.

A Educação Física, dentro do que se propõem os Parâmetros Curriculares Nacionais (BRASIL, 1998, p. 62), é a área do conhecimento que introduz e integra os alunos na cultura corporal do movimento, com finalidades de lazer, de expressão de sentimentos e de melhoria da qualidade de vida. Nesse sentido, busca garantir a todos a possibilidade de usufruir dos jogos, esportes, danças, lutas e ginástica em seu próprio benefício.

Segundo Sheila Scraton (1992, p. 53 apud LOURO, 1997, p. 73), comentando a 
bibliografia utilizada pela Educação Física no final dos anos 1960, "considera-se as mulheres como homens diminuídos: como 'homens truncados' ou 'homens pela metade'". Para a autora, são ideias como essas que vêm impedindo que seja realizado pelas meninas jogos ou atividades físicas tidas como masculinos ou, nas condições mais favoráveis, obrigam a que se adaptem ou se criem novas regras para os jogos como forma de ajustamento à capacidade enfraquecida das meninas.

Muitas pesquisas buscam acompanhamentos e respostas para tais comportamentos diferenciados, e dentre tantas há que, Barrie Thorne (1993, apud LOURO, 1997, p. 78), em pesquisa com crianças pequenas, descreve várias situações de brincadeiras entre os meninos e meninas. Ela fala que a escola favorece esse agrupamento por gênero, mais que em outras situações ou lugares, o que decorre muitas vezes por ser a escola uma organização que reúne muitas pessoas ou que também está sempre avaliando os alunos:

A separação de meninos e meninas é, então, muitas vezes, estimulada pelas atividades escolares, que dividem grupos de estudo ou que propõem competições. Ela é provocada, por exemplo, nas brincadeiras que ridicularizam um garoto, chamando-o de "menininha", ou nas perseguições de bandos de meninas por bandos de garotos. Por outro lado também se constrói na escola uma série de situações que representariam um "cruzamento de fronteiras", ou seja, situações em que as fronteiras ou os limites entre os gêneros são atravessados.

Comparando a citação acima é possível relacioná-la aos momentos complicados que acontecem na escola em que as pessoas que participam desse contexto muitas vezes ainda criam separações entre os meninos e as meninas nas brincadeiras ou competições esportivas. Questões como essas nos levam a pensar sobre o problema da diferença e da desigualdade no ambiente escolar envolvendo os meninos e as meninas nas práticas esportivas.

Para buscar resposta ao meu questionamento e dar continuidade à análise dos dados da pesquisa, sigo o apoio e incentivo de Louro (1997, p. 85) quando diz:

Se admitirmos que a escola não apenas transmite conhecimentos, nem mesmo apenas os produz, mas que ela também fabrica sujeitos, que produz identidades étnicas, de gênero, de classe; se reconhecemos que essas identidades estão sendo produzidas através das relações de desigualdades; se admitimos que a escola está intrinsecamente comprometida com a manutenção de uma sociedade dividida e que faz isso cotidianamente, com a nossa participação ou omissão; se acreditamos que a prática escolar é historicamente contingente e que é uma prática política, isto é, que se transforma e pode ser subvertida; e por fim, Revista Univap, São José dos Campos-SP, v. 17, n. 30, dez.2011. ISSN 2237-1753 
se não nos sentimos conformes com essas divisões sociais, então, certamente, encontramos justificativas não apenas para observar, mas, especialmente, para tentar interferir na continuidade dessas desigualdades.

Seguindo a citação da autora, entende-se que seja possível ocorrer transformações em toda a sociedade por meio da escola e suas relações de poder, procurando amenizar as distinções entre os seres, porém é necessário que haja disposição e determinação para interferir que essas desigualdades continuem prejudicando os que se sentem excluídos.

\section{METODOLOGIA DA PESQUISA}

Com o presente estudo, investiga-se as questões referentes às dificuldades, desigualdades e momentos de inclusão/exclusão, que o gênero feminino vivencia e presencia na escola, a partir de uma pesquisa desenvolvida na sala de aula envolvendo a leitura, interpretação e compreensão textual. Foram estabelecidas três turmas das sétimas séries do período vespertino do segundo semestre de 2010 para ler, estudar e analisar o texto "Futebol também é coisa de menina", retirado da página 187 do livro didático de Língua Portuguesa do $4^{\circ}$ ano do ensino fundamental, de Angélica Prado e Cristina Hülle, uma reportagem publicada pela revista Recreio, da Editora Abril, do mês de maio de 2000.

Os sujeitos da pesquisa foram 25 meninos e 28 meninas entre 12 e 14 anos de idade das sétimas séries do período vespertino da E.E.B. Natálio Vassoler, no bairro Vila Franca do município de Forquilhinha (SC). A escolha dessas turmas se justifica por serem elas as turmas nas quais a pesquisadora leciona Inglês, e que facilitou utilizar duas dessas aulas para desenvolver um trabalho direcionado à aquisição dos dados da referida pesquisa.

Utiliza-se, para discussão e análise dos dados, o material (relatos das opiniões dos alunos) coletado nas três turmas de sétimas séries, pois pretende-se saber como os meninos e as meninas integrantes desse meio são percebidos por eles mesmos durante a leitura de um texto, relativamente à função que a menina desempenha na sociedade, ou seja, se elas se percebem incluídas ou excluídas, principalmente nas atividades esportivas e mais especificamente no jogo de futebol na escola. Logo após a leitura do texto, discussão e entendimento, foi proposto um exercício de produção textual escrito no qual cada aluno deveria expor sua opinião e seus argumentos em relação ao tema problematizado em sala de aula.

\subsection{Analisando as relações entre as meninas e os meninos nas práticas esportivas na escola}

Da análise do texto, pode-se obter subsídios que levem a compreender de que maneira as pessoas revelam suas ações, pensamentos, intenções e de que maneira estabelecem relações sociais e individuais no ambiente onde vivem. Focou-se não somente a realidade particular desses alunos, mas ideologias que permitem ver e 
entender as opiniões e os comportamentos, sendo de um grupo social, de uma comunidade escolar ou a sociedade em geral.

O texto escolhido para desenvolver o estudo na sala de aula foi um texto do livro didático, sendo uma reportagem sob o título "Futebol também é coisa de menina" no qual se comenta que as meninas estão se preparando para as olimpíadas no Brasil. Para atingir o sucesso esportivo, as meninas precisam ficar longe de suas famílias, treinarem bastante, fazer ginástica e correr muito. As meninas se esforçam muito para serem jogadoras de futebol e ficam muitas vezes até sem comer ou dormir devido a treinos. A exposição final do texto ressalta que mesmo com muito trabalho, as garotas adoram jogar e fazem-no muito bem.

A proposta seria fazer uma relação entre a mensagem do texto à realidade vivenciada nas atividades esportivas na escola, apresentando, por escrito, argumentos favoráveis ou contraditórios sobre o tema comentado para assim perceber se havia 0 sentimento de desigualdade no ambiente escolar na colocação dos pesquisados.

Percebe-se, pela análise dos textos produzidos pelos pesquisados, que vinte e oito das falas das meninas, ou seja, $100 \%$ delas demonstram como ainda está presente o sentimento das desigualdades $e$ exclusões relacionadas à função do gênero feminino nas atividades esportivas da escola, as quais são provocadas mais especificamente pelos pensamentos contraditórios dos meninos e algumas vezes pela falta de iniciativa e tomada de providências das pessoas envolvidas naquele ambiente.
Os meninos da sala não deixam nós jogar porque dizem que futebol é coisa para meninos e falam para a professora não deixar nós jogar. Mas esse preconceito tem que parar porque o texto mesmo diz que futebol também é coisa de menina (menina 6).

Contudo, nove das meninas intensificam seus argumentos pela defesa da luta pelos seus direitos de poder realizar as mesmas atividades esportivas que os meninos fazem.

É muito raro quando jogamos, pois nós meninas estamos excluídas da atividade. Os meninos são os primeiros a nos excluir, a fala é sempre a mesma, futebol é coisa para nós, vocês são fracas, vocês não sabem jogar, com isso a professora acaba cedendo e tirando nosso lugar do jogo. Eu acho uma grande bobagem, pois já existem meninas que começaram uma grande carreira profissional de futebol na escola, e hoje estão muito conhecidas no mundo. Eu acho que, independentemente do sexo, devemos ter o lugar no futebol. $\mathrm{E}$ se o mundo de hoje acordar e ver que nós também somos capazes e se os meninos acabarem com essa bobagem de exclusão, eles poderão ser surpreendidos por nós. Por isso, meninos, acordem, não é só porque vocês do sexo masculino que vocês são melhores que nós 
meninas. Chega de exclusões (menina 2).

Percebe-se também que seis meninos demonstram resistência quanto à participação das meninas nas atividades como o futebol, achando que elas não sabem jogar, que fazem tudo errado e que esse esporte é adequado somente para os homens.

As meninas não sabem jogar. Elas só dão caneladas, futebol é só pra os homens (menino 2).

Esses meninos encontram todos os tipos de motivos para afastar a ideia de que as meninas pratiquem esse esporte.

Alguns meninos não deixam as meninas jogar futebol porque as meninas são ruins, são lentas, enfim, elas não sabem jogar futebol não sabem chutar, não sabem cruzar, enfim, as meninas são muito tensas para jogar futebol, então é só isso (menino 21).

Dentre os vinte 25 meninos entrevistados 19 deles até percebem e comentam a atitude dos colegas em relação ao futebol praticado pelas meninas, porém não são tão contraditórios ao fato e concordam que as meninas têm capacidade de enfrentar as exigências do futebol, porém 12 deles até reconhecem que elas merecem jogar futebol.

As meninas da escola não sabem jogar futebol. Elas dão muitas caneladas e chutam errado a bola e batem direto etc. mais tem algumas meninas que jogam bem no futebol, chutam certo, passam certo, não berram etc., mais essas meninas merecem jogar futebol, mais as outras não, mais o futebol é feito para todas as meninas do mundo, mais para jogar futebol serio como nas olimpíadas como a seleção do Brasil feminino tem que se esforçar tem que jogar serio para ser uma jogadora boa (menino 1$)^{2}$.

Das análises realizadas, considera-se que as relações entre os alunos envolvidos na pesquisa são construídos historicamente e obedecem a um determinado padrão construído socialmente ou relacionado aos fatos que acontecem e conforme as habilidades individuais ou, às vezes, dos grupos ao qual pertencem. Conforme os Parâmetros Curriculares (1998, p. 108), a atribuição de valores ao sucesso e ao fracasso, ao acerto e ao erro, ao jeito e à falta de jeito pode ser vista por meio das relações que o grupo estabelece com a competição e também com os valores do ambiente sociocultural no qual o grupo está inserido. Para tanto, o documento define como função do professor despertar a reflexão crítica sobre esses valores, possibilitando, assim, uma interferência no ambiente sociocultural vivenciado e apresentado pelos alunos, comprovando a necessidade da cooperação, da participação e de que haja respeito entre eles.

Seguindo essas orientações, fica a cargo do professor, então, observar como se

\footnotetext{
2 Todos os comentários dos pesquisados estão de acordo com a produção textual escrita deles realizada no momento da pesquisa.
} 
apresentam as relações afetivas dentro do grupo e se permitem que seus integrantes sintam-se seguros em compartilhar seus sucessos e fracassos, para que sintam prazer na atividade em grupo a ponto de motivar-se a enfrentar e vencer os desafios. Em síntese, o documento declara: "Essa autoconfiança se constrói na medida em que acertar ou errar é visto e valorizado como parte integrante do processo de aprendizagem".

Para Louro (2001, p. 91), "[a] produção de identidade de gênero 'normais' também pode representar a obrigatoriedade de 'preferir' determinados interesses, se desenvolver habilidades ou saberes compatíveis com as referências socialmente admitidas para masculinidade e para feminilidade". $\mathrm{Na}$ visão da autora, as consequências disso podem até implicar desconforto, para meninos ou meninas, diante de atividades ou práticas estabelecidas como características normais de seu gênero, na exigência de ter sucesso naqueles setores em que os homens ou as mulheres na realidade desempenham bem.

As meninas não são tão boas como os guris. Os guris detestam jogar futebol com as gurias, hoje tem professores que dá bastante oportunidades pra as meninas jogarem, os guris dizem que as meninas são perna-de-pau. Mas também tem menina que é melhor do que eles, claro que é só no máximo 3 cada sala, as meninas não gosta mais de futebol do que de vôlei, mas já estamos acostumados com isso (menina 25).

Em alguns poucos casos existe 0 reconhecimento de tal habilidade e a percepção de que algo deve ser feito para que haja mudanças nesse local. No entanto, acabam por aceitar as circunstâncias ocorridas nas aulas, criando um lugar de distinções marcado pelas diferenças entre os gêneros.

Para Louro (2001, p. 91), "[a] escola e o currículo estão longe de ser meros reflexos das condições sociais". A autora refere-se às múltiplas práticas cotidianas e banais, afirmando que pelos gestos e expressões que são pouco perceptíveis, pelo silêncio ou pela fala, é que se constroem na escola lugares distintos, sociais, entre eles: identidades de gênero e sexuais, identidades de classe e de etnia, marcados pela diferenciação e pela hierarquia. No entanto, ela chama atenção e recomenda que não deixemos de perceber o quanto estamos neles implicados e o quanto somos responsáveis por essas condições.

Para Sartori e Britto (2004, p. 55), "[a] escola, em moldes tradicionais, ensina, pune, castiga, insiste nos moldes de meninas delicadas, doces, passivas, afáveis, altruístas, frágeis, emocionais, 'femininas' e de meninos, 'agressivos', ativos, inquietos, egoístas, fortes, 'durões', 'masculinos'”. Em relação a esse pensamento nota-se que as pessoas percebem quando os meninos criticam as meninas:

Quando meninas jogam os meninos ficam estressados porque dizem que elas são lentas, tensas e não sabem jogar (menino 24).

Em contrapartida a essas considerações tradicionais e a opinião de alguns meninos da turma pesquisada, os 
autores declaram que os sujeitos são concretos, as pessoas são de 'carne e osso', não se curvam tão simplesmente a essa padronização de comportamentos. Para os autores acima, a escola sempre esteve cheia de meninas ativas $e$ às vezes agressivas, assim como sempre foi um lugar, tão ou mais sofrido, de meninos delicados, sensíveis, às vezes femininos.

$\mathrm{Na}$ verdade, o que os estudos de gênero vêm demonstrando é que masculino ou feminino não se apresentam nos sujeitos de uma forma estabelecida pelo pensamento de cada um, como, por exemplo, quando comparamos algo na cor-de-rosa à menina e o azul ao menino. As características de um e de outro não são definidas e nem fixas. Essas características são culturais e históricas, o que quer dizer que podem mudar de uma sociedade para outra, ou numa mesma sociedade, e podem mudar até mesmo com o tempo. Nesse caso, Sartori e Britto (2004, p. 56) dizem que "os estudos demonstram que a masculinidade e feminilidades se constroem nessas relações. As pessoas, independentemente do sexo, precisam ser mais "masculinas" e, em outras, mais "femininas".

Sintetizando a ideia desses autores, a escola não se dá conta de que produz pessoas infelizes, por não se ajustarem a um modelo irreal ou porque se comportam a duras penas, mas não se satisfazem e sofrem com isso. Esses autores acrescentam que, além de tudo isso, a escola não revê esses preconceitos e vai produzindo possíveis cidadãos preconceituosos que irão reproduzir em suas vidas, para além do espaço escolar, as discriminações e exclusões ali aprendidas.

No entanto, não se pode encarar isso como fato único e buscar incluir no cotidiano escolar o que os Parâmetros Curriculares Nacionais para Educação Física (1998, p. 90) apresentam como objetivos aos alunos que frequentam o final do terceiro e quarto ciclo do ensino fundamental:

Participar de atividades de natureza relacional, reconhecendo e respeitando suas características físicas e de desempenho motor, bem como a de seus colegas, sem discriminar por características pessoais, físicas, sexuais ou sociais. Apropriar-se de processos de aperfeiçoamento das capacidades físicas, das habilidades motoras próprias das situações relacionais, aplicando-os com discernimento em situações-problema que surjam no cotidiano.

Analisando a citação do documento, ressalta-se que é muito mais produtivo um trabalho onde há a participação dos alunos e o respeito entre eles nas atividades escolares; no entanto, é necessário levar em conta a influência de outros elementos exteriores como as relações familiares e suas atribuições na sua formação.

Realmente, existem muitas influências além da escola, pois num artigo sobre "A construção de novas identidades de gênero" de Marília Pinto de Carvalho, da revista Pedagogia Contemporânea, do mês de setembro (2009, p. 86-87), a autora apresenta um destaque de Connell: contudo 
"é importante dizer que a escola não é a única instituição a influenciar as masculinidades e pode não ser a mais importante, pois também atuam intensamente nesse processo a família e a mídia, entre outras instituições sociais". Connell reforça que a escola é apenas uma entre as diversas instituições atuantes nessa dinâmica, a qual exerce o papel que não é exclusivo, mas também não pode ser descartado.

Percebe-se, neste estudo, que as justificativas para as desigualdades precisam ser buscadas não nas diferenças biológicas, mas nas relações e envolvimentos com os colegas que pertencem à turma. Contudo, as meninas ao participarem dos eventos esportivos com os meninos, nessa escola, enfrentam desafios devido à própria discriminação em relação ao gênero feminino, que considera as meninas que jogam futebol, as fracas e que não conhecem nada sobre a modalidade.

Seguindo a orientação dos Parâmetros Curriculares (1998, p. 101-102), nota-se que há a falta de critérios para avaliação no sentido de realizar as práticas da cultura corporal do movimento nesse espaço. Esse documento orienta tal avaliação e requer uma observação em relação ao aluno verificando se ele faz as atividades, agindo de maneira cooperativa, integrada ao grupo, e se mantém o respeito entre os colegas. Segundo essa abordagem, para amenizar a situação de desigualdades tanto o professor quanto todos os profissionais da escola podem observar se 0 aluno realiza as atividades, reconhecendo e respeitando suas características e desempenho físico, bem como dos colegas, sem discriminar por características pessoais, físicas, sexuais, culturais, históricas ou sociais.

\section{CONCLUSÃO}

Considera-se que as desigualdades que envolvem os gêneros: masculino e feminino seja um tema que gera muita polêmica, sobretudo quando se percebe que no meio escolar ainda existe uma tendência histórica e cultural, por parte dos meninos e também por outras pessoas que com eles convivem, ao tratarem a questão do gênero de forma diferenciada, firmando distinções entre os meninos e meninas nas atividades esportivas, e se afastando de qualquer transformação em relação à forma de convivência que interferem no envolvimento esportivo das meninas nesse contexto escolar.

Percebe-se que a condição das relações sexistas no ambiente das turmas pesquisadas reafirma a desigualdade entre os sexos e a divisão das funções sociais e que eles continuam seguindo os valores construídos socialmente e transferidos por várias gerações como verdades únicas.

Entende-se que os argumentos dos autores, que deram suporte a este estudo e durante as discussões apresentadas, são no sentido de assumirmos que esta pode ser uma importante oportunidade de vivências esportivas para os meninos e as meninas, permitindo as habilidades existentes nas práticas esportivas do ambiente escolar.

Isso significa que somente numa parceria eles poderão buscar, de forma respeitosa, a igualdade de chances entre os gêneros, fatores esses necessários para uma construção de relações entre os seres considerados iguais e que podem 
desencadear uma mudança no local social onde convivem.

Conclui-se, com base nas análises feitas dos relatos em relação ao texto "Futebol também é coisa de menina" e dos alunos pesquisados, que as relações das quais se apresentam nas atividades esportivas na escola, entre meninos e meninas, quando vivenciam o futebol na E.E.B. Natálio Vassoler, em Forquilhinha (SC), contribuem para permanecer algumas relações constrangedoras entre os sujeitos masculinos e femininos, construídas e firmadas pela sociedade como valores históricos reais, priorizando, assim, o masculino em relação ao feminino, caso não haja providências com intuito de reformular os critérios já estabelecidos para tal situação.

\section{REFERÊNCIAS BIBLIOGRÁFICAS}

BRASIL. Secretaria da Educação Fundamental. Parâmetros Curriculares Nacionais: terceiro e quarto ciclos do ensino fundamental: introdução aos Parâmetros Curriculares Nacionais. Brasília: MEC/SEF, 1998. 174 p.
- Secretaria de Educação Fundamental. Parâmetros Curriculares Nacionais: Educação Física. Brasília: MEC/SEF, 1998. 114 p.

CARVALHO, M. P. C. Raewyn Connell: A construção de novas identidades de gênero, Revista Pedagogia Contemporânea, p. 8687, setembro, 2009.

FOUCAULT, M. Vigiar e Punir. 29. ed. Petrópolis: Vozes, 2004.

LOURO, G. L. Gênero, sexualidade e educação: uma perspectiva pósestruturalista. Petrópolis. Vozes, 1997.

- O currículo e as diferenças sexuais e de gênero. In: COSTA, Mariza v. (org.) 0 currículo nos liminares contemporâneos. 3. ed. Rio de Janeiro: P\&A, 2001.

MONTEIRO E. Futebol também é coisa de menina. Revista Recreio, Editora Abril, p. 18, 18 de maio de 2000.

SARTORI, A. J.; BRITTO, N. S. Gêneros na educação: espaço para diversidade. Florianópolis: Genus, 2004. 120 p. 